\title{
CFD Simulation of Energy-Saving Airflow Organization in a Multifunctional Kitchen
}

\author{
Kun Zhang ${ }^{1, a^{*}}$, Jinling Wang ${ }^{1, b}$ and Silong Zhang ${ }^{2, c}$ \\ ${ }^{1}$ Harbin Engineering University, Harbin, China \\ 2 Tianjin Jin'An Thermal Power CO.,LTD, Tianjin, China \\ a zhangkunzk00@163.com, ${ }^{\mathrm{b}}$ wangjinling07@163.com , ${ }^{\mathrm{c}}$ zhangsilong008@163.com
}

\begin{abstract}
Keywords: Ventilation system; Air-conditioning system; Multifunctional kitchen; Airpak3.1
\end{abstract}
Abstract. Efficient ventilation and sound air current are significant to improve indoor air quality (IAQ) and control the contamination concentration. Healthy and comfort air-conditioning will provide a strong guarantee for high-performance work. While limited by lots of conditions, the airflow distribution in room is very difficult to be revealed, so numerical simulation and analysis for airflow organization become more and more important during the design stage of ventilation and air-conditioning system. In this paper a multifunctional kitchen is taken as a model to do simulation analysis on the effect of heat source. On the basis of computational fluid dynamic (CFD) theory and methodology, the temperature fields and velocity fields are obtained by means of Airpak3.1. All these search works will be helpful for the further design and optimization for the ventilation and air-conditioning system. Finally it will realize the ultimate goal of energy saving and emission reduction.

\section{Introduction}

Recently, CFD is widely applied in the HVAC field, Willers investigated the effect of kitchen ventilation (while cooking) on the relationship between gas cooking, combustion product dispersal, and respiratory and allergic outcomes in children [1]. Zou proposed that mechanical ventilation must be adopted in residence kitchen, he also studied the ventilation characteristics with the help of CFD analysis method. Concluded that in the aspects of building design, if inlets and outlets of the kitchen in residence were well arranged, a good airflow distribution would be acquired, the contamination in kitchen would be exhausted effectively and the indoor air quantity of the kitchen would be improved[2]. Yang used CFD to analyze the different schemes of the kitchen ventilation. Which provided a guidance of the design of the kitchen layout by the comparing the effect of different layouts and obtained a comparative better scheme by analyzing the velocity field[3].

In contrast to the earlier work, this paper focuses on the effect of the heat source on a multifunctional kitchen with the help of the Airpak3.1. Airpak is a powerful, quick, and easy-to-use CAE software design tool for ventilation systems that are required to deliver indoor air quality (IAQ), thermal comfort, health and safety, air conditioning, and/or contamination control. Airpak provides designers with the ability to rapidly create and mesh models of their problems without the time-consuming process characteristic of general-purpose software and without the compromised geometries characteristic of dated ventilation software programs. Moreover, the solution process is streamlined with well-chosen default selections of models and solution parameters so that inexperienced users can obtain reliable results quickly. Finally, Airpak provides state-of-the-art.

\section{Physical Model}

A multifunctional kitchen shown in the figure. 1 is applied to study the airflow organization. The multifunctional kitchen includes three adjoining rooms with two doors: the pre-processing room, the staple food processing room and the cooking room. The extraction hoods are in cooking room just above the hearths. The ventilation system contains two natural vents located at the ceiling of the preprocessing room and 
cooking room respectively, and three air-conditioning(AC) supply vents with two located at the ceiling of cooking room and one of the preprocessing room. Six mechanical replenishment(MR) air vents are located at the ceiling of the cooking room. The simulation includes two cases with the first one the hearths do not work, and the second one the hearths in working state. The air-conditioning design parameters are shown in Table 1. In which, $T_{\mathrm{o}}$ is the outdoor dry bulb temperature, $T_{\mathrm{i}}$ is the indoor dry bulb temperature, $T_{\mathrm{s}}$ is the supply air temperature, $S$ is he heat source from hearth, $V_{\mathrm{s}}$ is the supply air volume and $V_{\mathrm{e}}$ is the exhaust air volume.

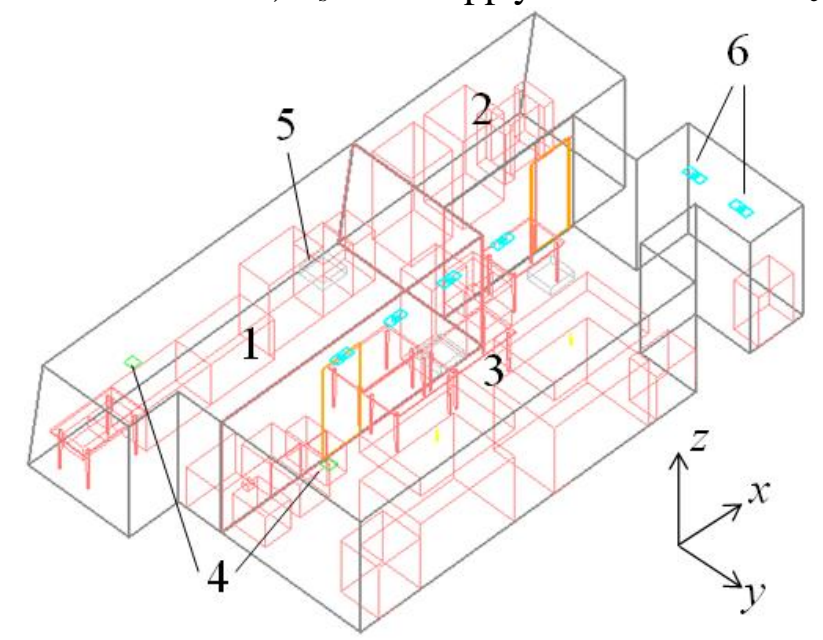

1.Preprocessing room; 2.Staple food processing room; 3.Cooking room; 4.Natural vent; 5.Supply air vent; 6.Mechanical replenishment air vent

Figure1. Kitchen model

Table 1. Air-Conditioning design parameters

\begin{tabular}{c|c|c|c|c|c|c}
\hline Cases & $T_{0}\left[{ }^{\circ} \mathrm{C}\right]$ & $T_{\mathrm{i}}\left[{ }^{\circ} \mathrm{C}\right]$ & $T_{\mathrm{s}}\left[{ }^{\circ} \mathrm{C}\right]$ & $S[\mathrm{~kW}]$ & $V_{\mathrm{s}}\left[\mathrm{m}^{3} / \mathrm{h}\right]$ & $V_{\mathrm{e}}\left[\mathrm{m}^{3} / \mathrm{h}\right]$ \\
\hline Case1 & 35 & 27 & 17 & 0 & 5200 & 5800 \\
\hline Case2 & 35 & 27 & 17 & 60 & 5200 & 5800 \\
\hline
\end{tabular}

\section{Numerical Method}

Laminar and turbulent flow are the two basic flow states. While Reynolds number $R e$ is less than $\operatorname{Re}_{\text {crit }}$ (critical Reynolds number) the flow is in laminar state, and it will gradually evolve into turbulent state when $\mathrm{Re}$ is greater than $\mathrm{Re}_{\text {crit }}$. The turbulent is the most common flow phenomena in nature, and in most engineering problems the fluid flow is in turbulent state. The air flow in the multifunctional kitchen belongs to incompressible viscous fluid in turbulent state. The zero-equation model is chosen to simulate different operating conditions. Generally, it believed that no matter how complex the turbulence is the Navier-Stokes equations are still applicable[4].

The universal equation for mass, momentum and energy conservation equation can be written as Eq.(1):

$$
\operatorname{div}(\rho V \phi)=\operatorname{div}(\Gamma \operatorname{grad} \phi)+S
$$

\section{Boundary Condition and Grid Generation}

The actual physical model of kitchen airflow is very complex, some simplifications have been made. It assumes that incompressible air is continuous media flowing in steady state. Air tightness of the kitchen is very good, so it will ignore the impact of air infiltration through the door. 
Vent inlets are treated as velocity and temperature boundary, a pressure outlet is defined at the exit boundaries and no-slip conditions are applied to all surfaces of the kitchen shape, hearths are set to heat sources. About 600 millions structured grids are generated.

\section{Simulation Results}

The average temperature in the kitchen is $26.8^{\circ} \mathrm{C}$ when there is no heat source, and the average pressure is $-42 \mathrm{~Pa}$, which guarantees the exhaust is a smoothly process. While when the hearths are in working, the average temperature of the kitchen raises by $1.2^{\circ} \mathrm{C}$. The particle trace in figure 2 shows that the characteristics of airflow out from $\mathrm{AC}$ vent and $\mathrm{MR}$ vent are dramatically different. The $\mathrm{AC}$ airflow will adherence of the ceiling firstly, after driving a short distance, it turnes down blowing into the cooking room. The AC airflow usually covers a wide range, while it experiences a rapid rise of the temperature. At a distance of $0.2 \mathrm{~m}$ below the vent, wind temperature is $24^{\circ} \mathrm{C}$, and the average temperature above the height of $1.8 \mathrm{~m}$ is $27^{\circ} \mathrm{C}$. For MR airflow, it turns down directly out from the vent with a high speed, and covers a small rang in the horizontal direction. It can maitain a lower temperature of $21^{\circ} \mathrm{C}$ on the ground, as it arrives at a better refrigeration effect.

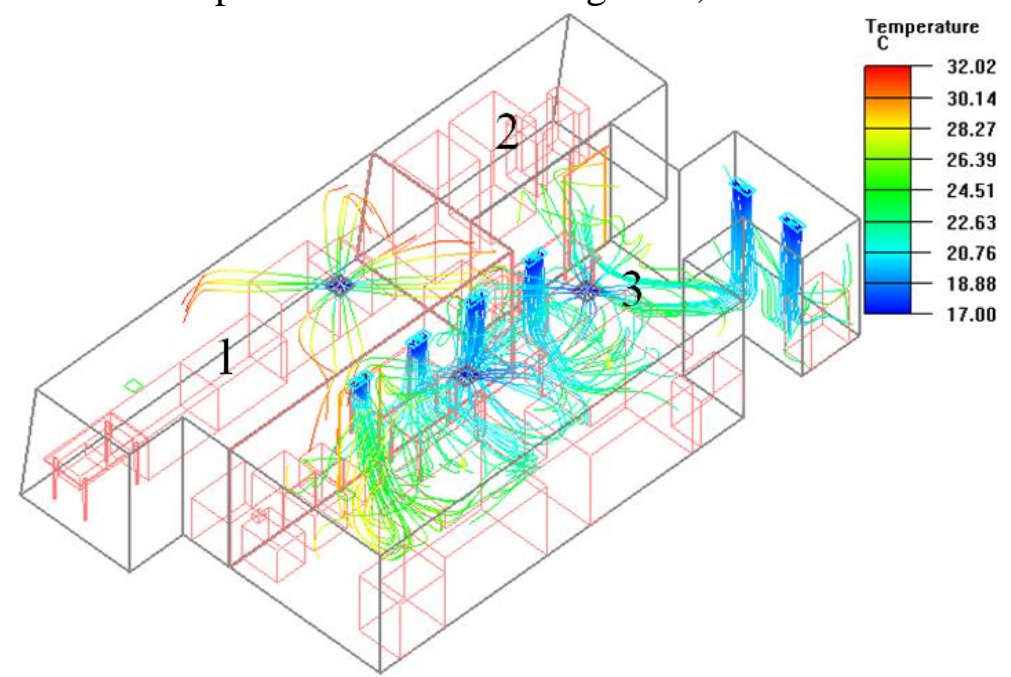

Figure 2. The particle trace in the kitchen

The temperature distribution of different slices are shown in Fig.3. The simulation results demonstrate that the cooking room obtains the lowest temperature of $26.6^{\circ} \mathrm{C}$, in the region near the hearth the temperature is about $37^{\circ} \mathrm{C}$. In the workspace the average temperature is $24^{\circ} \mathrm{C}$, which is a comfortable level and may avoid the burning sense.

The preprocessing room communicates with the cooking room with a ventilating grill on the door, and the airflow organization in this room is upper send and upper return, and the average temperature in the room is $28^{\circ} \mathrm{C}$.

In the staple food processing room there is neither air supply vent nor exhaust air vent, and it communicates with the cooking room with a door. The lower temperature air in the cooking room inrushed into the staple food processing room through the door to wipe out the heat load, with the average temperature of $28^{\circ} \mathrm{C}$.

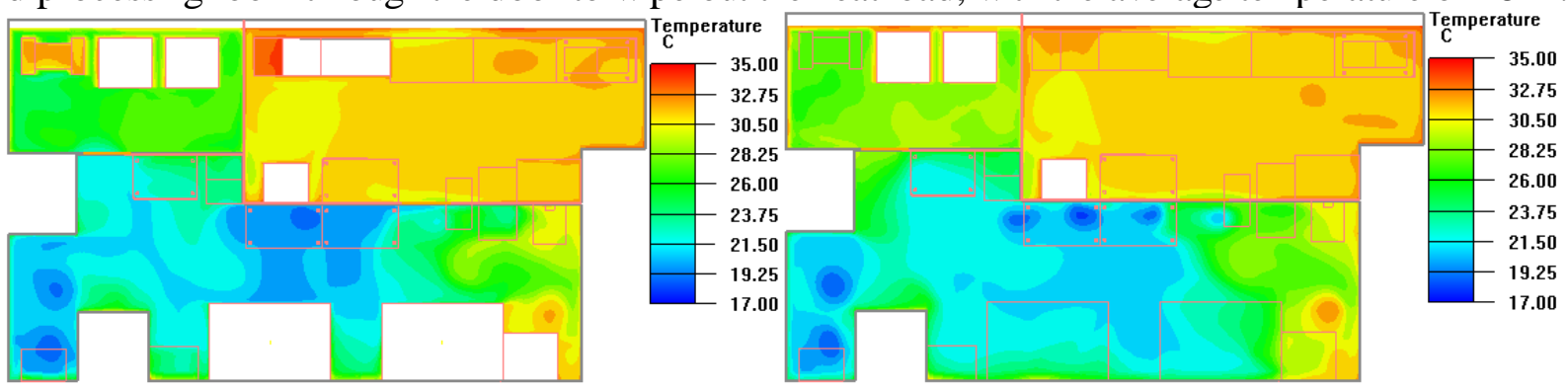

(a) $z=1.0 \mathrm{~m}, S=0 \mathrm{~kW}$

(b) $z=1.5 \mathrm{~m}, S=0 \mathrm{~kW}$ 


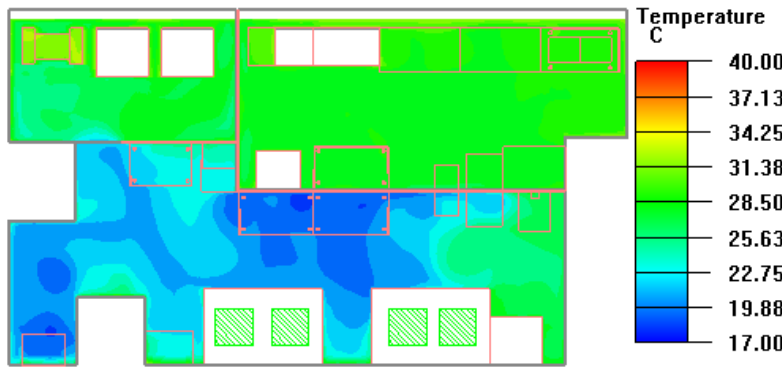

(c) $z=1.0 \mathrm{~m}, S=60 \mathrm{~kW}$

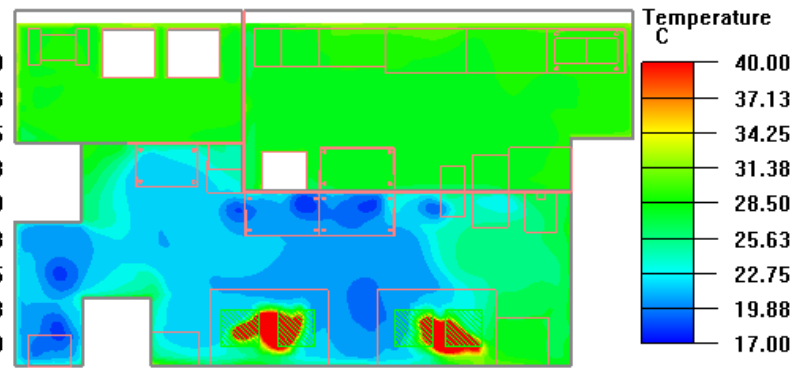

(d) $z=1.5 \mathrm{~m}, S=60 \mathrm{~kW}$

Figure 3. The temperature distribution of different slices

The velocity distribution of two slices of the workspace region are shown in Fig.4. In the cooking room a large quantity of air supply and the exhaust exist, so the airflow speed in this room is higher than that in the other two rooms. In the region of workspace the wind speed is higher than $0.6 \mathrm{~m} / \mathrm{s}$, the airflow is turbulent. Which is favourable to exclude the heat from the hearths, and keep a comfortable thermal environment. The airflow in the preprocessing room and the staple food room is gentle and the average wind speed is $0.3 \mathrm{~m} / \mathrm{s}$, which is not big enough to cause cold draft.

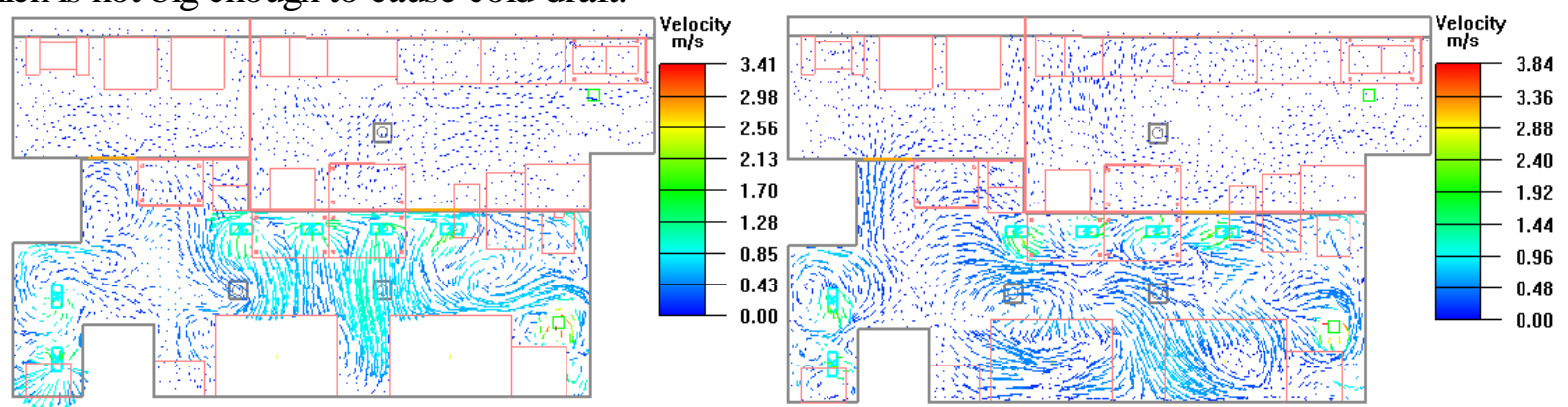

(a) $z=1.0 \mathrm{~m}, S=0 \mathrm{~kW}$

(b) $z=1.5 \mathrm{~m}, S=0 \mathrm{~kW}$

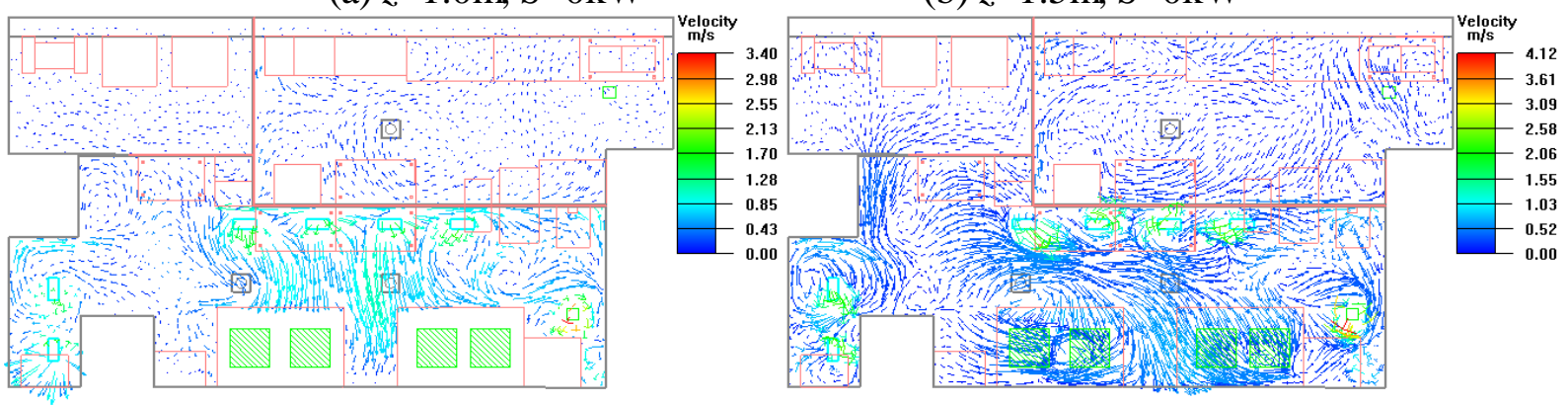

(c) $z=1.0 \mathrm{~m}, S=60 \mathrm{~kW}$

(d) $z=1.5 \mathrm{~m}, S=60 \mathrm{~kW}$

Figure 4 . The velocity distribution in two slices

\section{Summary}

For the ventilation designers it is very important to predict airflow so as to discover the advantages and disadvantages in the design stage. Which can avoids waste of time and money from unreasonable airflow program. The comparative analysis of the impact heat source on airflow in a multifunctional kitchen demonstrates that when the hearths are in opening state, the average temperature and the turbulivity will increase markedly. The results shows that the various indexes in kitchen all comply with the desgin standard, so the combination of the ventilation and air-conditioning system is an optimized operation. It is expected to provide a reference basis for kitchen ventilation system design so as to create the better IAQ and use less energy and getting the optimal comfort. Finally it will realize the ultimate goal of energy saving and emission reduction. 


\section{References}

[1] S. M. Willers, Gas Cooking, Kitchen Ventilation, and Asthma, Allergic Symptoms and Sensitization in Young Children - the PIAMA study, J. Allergy. 61(2006) 563-568.

[2] J. Yang, The Numerical Simulation of Kitchen Ventilation, J. Refrigeration and Air-Conditioning. 1(2007) 91-93.

[3] S. H. Zou, Numerical Analysis of the Ventilation of a Kitchen in Residence, J. Engineering Science. 6(2004) 70-72.

[4] G. R. Dou. Mechanics of Turbulence. Beijing, 1985. 